\title{
Cartagena: nuevo foco de leishmaniasis visceral urbana en Colombia
}

\author{
Cartagena: New Urban Focus of Visceral Leishmaniasis in Colombia
}

\author{
C. P. Zambrano Hernández ${ }^{a}$,* \\ M. S. Ayala Sotelo ${ }^{\mathrm{a}}$ \\ O. P. Fuya Oviedo ${ }^{\mathrm{a}}$ \\ O. C. Barraza ${ }^{b}$ \\ G. Rodríguez Toro ${ }^{\mathrm{c}}$
}

Recepción: 10-sep-2015

Aceptación: 08-dic-2015

\section{Resumen}

En Colombia, la leishmaniasis visceral (LV) es de predominio rural, en áreas determinadas de algunos departamentos de la Región Caribe y en el valle medio del río Magdalena. Una niña de un año de edad, del área urbana de Cartagena, presentó síntomas de hepato-esplenomegalia, anemia, leucopenia y desnutrición; ella no había estado en áreas de riesgo para LV, tuvo pruebas serológicas positivas, reversó síntomas con Glucantime $^{\circledR}$, y luego de tres meses postratamiento su leishmanina fue positiva. Identificar la presencia de vectores, reservorios y condiciones ambientales para la transmisión de LV en el área del caso confirmado. Se realizaron estudios epidemiológicos, clínicos, inmunológicos y moleculares para buscar otros pacientes, reservorios y vectores. El área de estudio presentó condiciones que favorecen la transmisión de la enfermedad. No se encontraron otros niños enfermos. Siete personas adultas tuvieron resultado reactivo a la Prueba Intradérmica de Montenegro, indicando contacto previo con el parásito, y dentro de su vivienda se capturó $L u$. evansi. En un canino y en un Didelphis marsupialis se confirmó por laboratorio la infección por Leishmania infantum. Se demostró un foco urbano y nuevo de LV en Colombia que debe ser objeto de acciones regulares de salud pública.

Palabras clave: Didelphis marsupialis., Lutzomyia evansi, Leishmania infantum, Leishmaniasis visceral urbana.

\footnotetext{
Abstract

In Colombia, Visceral Leishmaniasis (VL) is predominant in rural areas of the Caribbean and Magdalena River Valley regions. A one year old female inhabitant of an urban zone in the city of Cartagena displayed symptoms of hepato/splenomegaly, anemia, leucopenia and malnutrition. She had not visited endemic areas for VL but tested positive for VL serologically. After treatment with Glucantime ${ }^{\circledR}$, her symptoms disappeared; however, three months later, her Montenegro test came out positive. To identify the presence

${ }^{a}$ Grupo de Parasitología, Dirección de investigación en Salud Pública, Instituto Nacional de Salud, Bogotá.

*Autor de correspondencia: cpilarzambrano@gmail.com

${ }^{\mathrm{b}}$ Grupo Biología y Control de Enfermedades Infecciosas, Universidad de Antioquia, Medellín.

${ }^{\mathrm{c}}$ Facultad de Medicina. Universidad de La Sabana, Chía, Cundinamarca.
} 
of VL vectors and reservoirs, and also environmental conditions suitable for VL transmission in the area of the reported VL case. There were carried out epidemiological, clinical, immunological and molecular studies to look for other people infected with VL. Also it was searched for VL reservoirs and vectors in the area. The study area presented environmental conditions suitable for VL transmission. No infected children were found, but seven adults had positive Montenegro tests, suggesting exposure to the parasite in this area. Additionally, the VL vector species $L u$. evansi was found inside some of these people's homes. Finally, a domestic dog and a D. marsupialis individual were also found to be infected with Leishmania infantum, confirmed by laboratory. It was demonstrated the presence of a new urban VL scenario in Colombia, which should be object of public health surveillance and acts in the studied area.

Key words: Didelphis marsupialis., Lutzomyia evansi, Leishmania infantum, urban visceral Leishmaniasis.

\section{Introducción}

La leishmaniasis visceral (LV) es una antropozoonosis que continúa siendo un importante problema de salud pública en Colombia. Los dos focos de transmisión, principalmente rural y periurbana, históricamente reconocidos, están ubicados en el norte del país (departamentos de Sucre, Córdoba y Bolívar) y en el valle medio del río Magdalena (departamentos de Cundinamarca, Tolima y Huila) [1]. El agente etiológico responsable de la enfermedad en las áreas endémicas es Leishmania infantum. Los vectores incriminados en la transmisión son Lutzomyia longipalpis y L. evansi [2] y los principales reservorios identificados son el Canis familiaris y el Didelphis marsupialis [3-6]. Los síntomas frecuentes son fiebre, anemia, hepatoesplenomegalia y pérdida progresiva de peso, y la mortalidad de los casos no tratados o tratados tardíamente suele ser elevada [7].

El caso confirmado que motivó este estudio se presentó en un paciente femenino de un año de edad, residente del barrio Lo Amador, de Cartagena, sin desplazamientos a áreas de riesgo, que consultó a "La Casa del Niño Hospital Infantil Napoleón Franco Pareja", de Cartagena, por presentar fiebre intermitente de $38-39{ }^{\circ} \mathrm{C}$ de más de un mes de evolución, acompañada de vómito frecuente, edema de los miembros y abdomen abultado. Al examen físico presentó palidez mucocutánea, hepatomegalia y esplenomegalia de $4 \mathrm{~cm}$ por debajo del reborde costal y desnutrición ( figura 1). Se diagnosticó: 1) Síndrome febril en estudio, 2) Síndrome linfoproliferativo, 3) Síndrome anémico, 4) Leishmaniasis visceral. En los exámenes de laboratorio se encontró: leucocitos: $2300 \times \mathrm{mm}^{3}$, hemoglobina: $6,3 \mathrm{~g} \%$, hematocrito: $13,3 \%$, plaquetopenia e hipoalbuminemia ( figura 1).

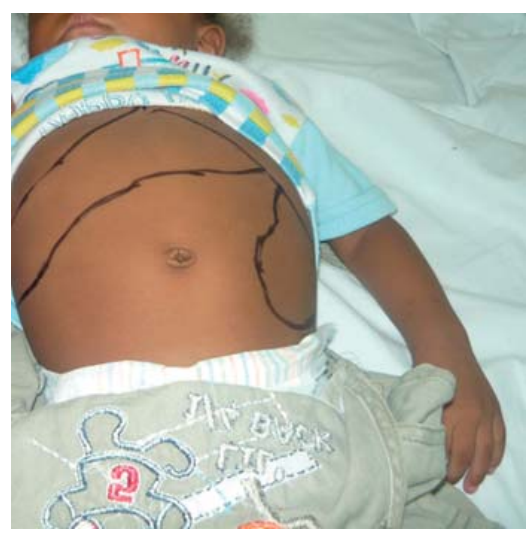

Figura 1. Fotografía niña con LV confirmada. Se observa hepato-esplenomegalia.

La prueba Kalazar Detect ${ }^{\mathrm{TM}}$ Human Rapid Test fue positiva. Se confirmó en el Laboratorio de Parasitología del Instituto Nacional de Salud (INS), por anticuerpos IgG para LV por IFI (título 1:32). Se trató con Glucantime ${ }^{\circledR}$ a dosis de $20 \mathrm{mg} / \mathrm{kg}$ de peso durante 28 días, con mejoría de su cuadro clínico. La niña presentó además dos úlceras extensas, irregulares, de fondo necrótico, en la frente y en el periné, que los médicos tratantes interpretaron clínicamente como leishmaniasis cutánea, sin confirmación por laboratorio, debido a que la muestra fue inadecuada para el estudio histopatológico y tampoco se le realizó diagnóstico molecular. A los tres meses de terminar el tratamiento se le practicó prueba de intradermorreacción de Montenegro (IDRM), la cual fue Reactiva.

El presente estudio tuvo como fin identificar la presencia de flebótomos, reservorios y condiciones ecológicas favorables para la transmisión de LV en el área urbana (barrio Lo Amador) de Cartagena. 


\section{Metodología}

\subsection{Encuesta en la comunidad}

Se diseñó una encuesta enfocada a identificar la conformación de las familias, número de personas, edad, ocupación y tiempo de residencia en el barrio; las características ecológicas del entorno y las condiciones habitacionales, para lo cual se recolectó la información sobre los materiales de las viviendas y la disposición de excretas y basuras; los conocimientos sobre la enfermedad, el vector, la forma de transmisión, las medidas de protección utilizadas para prevenir picaduras de insectos y la tenencia de animales domésticos. Se aplicaron 45 encuestas. Las personas encuestadas fueron adultos cuidadores de los niños, madre, padre o responsable del hogar. El tiempo de aplicación de la encuesta fue de 20 minutos por vivienda.

\subsection{Búsqueda Activa Comunitaria (BAC) e Institucional (BAI) de casos}

Se realizó búsqueda de casos en la comunidad, seleccionando niños, con preferencia menores de cinco años de edad, que presentaran síntomas compatibles con la enfermedad (desnutrición, hepatoesplenomegalia, infecciones a repetición, fiebre prolongada en los últimos tres meses). Para cada niño se diligenció una ficha clínica con la información sobre nombre, edad y sintomatología presentada. Se les tomó muestra de sangre, que se procesó para cuantificar la presencia de anticuerpos IgG contra Leishmania infantum, mediante IFI. Se practicó simultáneamente la prueba Kalazar Detect ${ }^{\mathrm{TM}}$ Human Rapid Test [8].

La búsqueda activa institucional se realizó en " $\mathrm{La}$ Casa del Niño Hospital Infantil Napoleón Franco Pareja", que atiende la mayor parte de la población infantil del Distrito de Cartagena y del departamento. Se realizó búsqueda sistematizada de las historias clínicas de los niños atendidos durante los últimos seis meses, mediante los códigos CIE 10, que tuvieran los diagnósticos de: síndrome febril prolongado: R50,1, R50,9; síndrome anémico: D63, D64; hepatoesplenomegalia en estudio: R16,0, R16,1, R16,2, y síndromes linfoproliferativos: 10 R59,0, R59,9, C96,0, C95,0, C95,9 y C96, sin evidencia de diagnóstico concluyente. Los pacientes resultantes de la búsqueda fueron captados para diagnóstico de LV mediante detección de anticuerpos IgG por IFI.

\subsection{Estudio de caninos con infección por Leishmania sp.}

Se informó a la comunidad sobre la necesidad de examinar los caninos del barrio y sobre las medidas de control que se implementarían en caso de encontrarse infectados (sacrificio humanitario), así mismo, se hizo énfasis en la tenencia responsable de mascotas y en la conveniencia de no tenerlas deambulantes (sin dueño). Se tramitó consentimiento informado de los dueños de los caninos que autorizaron el procedimiento. Se tomaron muestras de sangre de los 13 ejemplares caninos existentes en el barrio de estudio, que se procesaron para la detección de anticuerpos IgG por IFI contra Leishmania infantum y Kalazar Detect $^{\mathrm{TM}}$ Canine Rapid Test [9].

\subsection{Búsqueda de otros reservorios}

Para la captura de pequeños reservorios se siguió la metodología estandarizada [10]; el muestreo se realizó con un esfuerzo de captura, utilizando 15 trampas Tomahawk y 18 trampas Sherman para roedores. El diseño del muestreo correspondió a un juego de seis trampas Sherman ubicadas a $5 \mathrm{~m}$ de las viviendas y, luego, un juego de tres trampas Tomahawk a $10 \mathrm{~m}$ del grupo de trapas Sherman.

Las trampas se ubicaron tomando como referencia la residencia del caso índice (N10 25,194; W75 31,768; a $14 \mathrm{~m}$ ), iniciando el esfuerzo a $80 \mathrm{~m}$ del punto de referencia, que es el lugar donde comienza el bosque del Cerro de la Popa, y terminando en la parte más alta del cerro, hasta donde fue posible acceder (N10 25,216; W75 31,650; a 60 m); metodología que se aplicó durante dos noches.

A los reservorios capturados se les tomó muestras de sangre para cultivos en medio de NNN modificado y de tejidos (hígado, bazo y ganglio linfático), para análisis molecular. Para la PCR se eligieron los primeros Jvn11 (CCCACTATATTACACCAACCCCTA) y Jw12 (GGGTAGGGGCGTTCTGCGAAA) (el primer Jvn11 fue obtenido por modificación del primer Jw11 reportado previamente [11], para hacer más específica la detección de especies del género Leishmania spp. del Nuevo Mundo, tanto el subgénero Viannia como el subgénero Leishmania), produciendo una banda aproximada de $120 \mathrm{pb}$ en ambos casos. Un microlitro $(\mu \mathrm{L})$ del ADN extraido en cada ensayo se amplificó en una mezcla de reacción que contenía $2 \mathrm{mM}$ de $\mathrm{MgCl} 2,200 \mu \mathrm{M}$ de dNTP, 
$0,55 \mu$ de cada primer $1 \mathrm{x}$ de Taq Buffer y $1 \mu \mathrm{L}$ de Taq polimerasa en un volumen final de $25 \mu \mathrm{L}$. Para el control positivo se utilizó ADN de parásitos de referencia UA140, como control negativo de la reacción se utilizó agua en reemplazo del ADN. La amplificación se hizo en un termociclador MJ Research ${ }^{\circledR}$ con el siguiente perfil térmico: predesnaturalización de $94{ }^{\circ} \mathrm{C}$ por 4 minutos, 30 ciclos: desnaturalización a $90{ }^{\circ} \mathrm{C}$ por 1 minuto, alineamiento de $55^{\circ} \mathrm{C}$ y extensión de $72{ }^{\circ} \mathrm{C}$ por 30 minutos, seguidos de una extensión final de $72{ }^{\circ} \mathrm{C}$ durante 7 minutos.

El producto se visualizó por electroforesis en matriz de gel de agarosa (1.5\%) teñida con bromuro de etidio $(0,5 \mu \mathrm{g} / \mathrm{mL})$, utilizando controles positivos (Leishmania infantum y L. panamensis) y controles negativos (agua destilada y Trypanosoma cruzi).

Se remitieron muestras de tejido al laboratorio de Pesquisa em Leishmaniose Fundação Oswaldo Cruz del Instituto Oswaldo Cruz en Brasil, para la confirmación del diagnóstico molecular. La PCR fue realizada para una región de 234 pb del Gen HSP70, seguido de RFLP con enzimas de restricción [12].

\subsection{Estudio entomológico}

Los muestreos entomológicos se realizaron durante tres noches consecutivas, empleando trampas de luz CDC miniatura (seis con luz incandescente y una con luz ultravioleta); las trampas se dejaron instaladas de las 18:00 a las 6:00 horas. Se muestrearon 10 viviendas del barrio Lo Amador; en cada vivienda se hicieron muestreos en el intra y peridomicilio. Los flebótomos recolectados se preservaron en alcohol al $70 \%$, se aclararon con hidróxido de potasio al $10 \%$ y fenol líquido; a las hembras se les aplicó la técnica de disección de genitales descrita por Marcondes [13] y se utilizó la clave de Young y Duncan para su tipificación [14].

\subsection{Consideraciones éticas}

Según las normas éticas de la Declaración de Helsinki y la Resolución 8430 de 1993 del Ministerio de Salud y Protección Social de Colombia, y cumpliendo con los lineamientos establecidos a nivel ético del Instituto Nacional de Salud para la investigación de brotes, se presentó riesgo mínimo para los seres humanos. Para la toma de muestras en niños se informó a los pacientes y a sus madres o tutores sobre el procedimiento por seguir y la interpretación de los resultados. Se dispuso de consentimientos informados de los padres o tutores. Los resultados se comunicaron de forma individual. Se tuvo especial cuidado en garantizar la confidencialidad de todos los datos.

Para las muestras de caninos se informó a los propietarios sobre el proceso de la toma de muestra y la interpretación de los resultados, incluyendo la información sobre la pertinencia del sacrificio humanitario del animal en caso de confirmación de LV; se firmaron consentimientos. De igual forma, todos los procedimientos realizados en mamíferos domésticos y sinantrópicos se aprobaron por el comité de ética para experimentación animal de la Universidad de Antioquia en el acta no. 42 del 12 de mayo del 2008.

\section{Resultados}

\subsection{Encuesta en la comunidad}

El análisis descriptivo mostró que el promedio de personas que habitaban cada vivienda fue de 6,4 , con un mínimo de dos y un máximo de once. Las familias estaban conformadas por varios núcleos (familias extensas) que habitaban en un espacio reducido y con deficientes condiciones de salubridad.

Los encuestados fueron $81,4 \%$ mujeres y $18,6 \%$ hombres, con edad promedio de 39,1 años (17-76 años). El tiempo promedio de residencia de las familias en el barrio fue de 24 años, con un mínimo de un año y un máximo de 55. En cuanto a la ocupación de los individuos cabeza de familia, $60,5 \%$ fueron amas de casa; comerciantes, un $9,3 \%$, y auxiliares de enfermería, un 4,7\%. Otras ocupaciones fueron: modista, empleada doméstica, electricista, reciclador y albañil.

Las viviendas estaban rodeadas de bosque seco primario; en la parte trasera tenian un patio que limitaba con la zona de bosque del cerro, con libre acceso para la entrada de insectos y animales silvestres (figura 2). Los demás resultados se describen en la tabla 1.

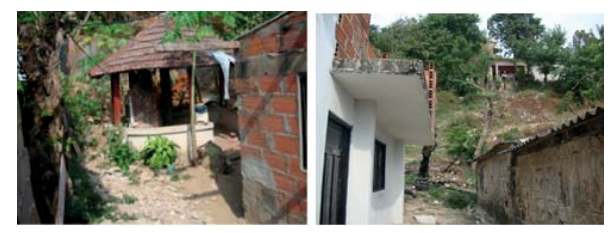

Figura 2. Viviendas del Barrio Lo Amador, Cartagena. 
Tabla 1. Resultados encuesta a la comunidad.

\begin{tabular}{|c|c|c|}
\hline \multicolumn{3}{|c|}{ Materiales de construcción de las viviendas } \\
\hline \multirow{3}{*}{ Paredes } & Ladrillo & $55,8 \%$ \\
\hline & Bloque & $25,6 \%$ \\
\hline & Cemento & $18,6 \%$ \\
\hline \multirow{3}{*}{ Pisos } & Baldosa & \\
\hline & Cemento & $20,9 \%$ \\
\hline & En tierra & $18,6 \%$ \\
\hline \multirow{3}{*}{ Techos } & Eternit & $72,0 \%$ \\
\hline & Zinc & $18,0 \%$ \\
\hline & Otros materiales & $10,0 \%$ \\
\hline \multicolumn{3}{|c|}{ Disposición de excretas } \\
\hline \multirow{3}{*}{ Sanitarios } & Baños & $72,0 \%$ \\
\hline & Letrinas & $7,0 \%$ \\
\hline & Campo abierto & $21,0 \%$ \\
\hline \multicolumn{3}{|c|}{ Disposición de basuras } \\
\hline \multirow{3}{*}{ Basuras } & Camión de recolección & $46,0 \%$ \\
\hline & Campo abierto & $42,0 \%$ \\
\hline & Incineración & $12,0 \%$ \\
\hline \multicolumn{3}{|c|}{ Conocimientos sobre la enfermedad } \\
\hline Asociacion de los & Sí & $16,0 \%$ \\
\hline sintomas con & Otra patologia & $12,0 \%$ \\
\hline Leishmaniasis visceral & No & $72,0 \%$ \\
\hline \multicolumn{3}{|c|}{ Conocimientos sobre el vector } \\
\hline \multirow{2}{*}{$\begin{array}{l}\text { Vector y mecanismo } \\
\text { de trasnmision }\end{array}$} & Sí & $21,0 \%$ \\
\hline & No & $79,0 \%$ \\
\hline \multicolumn{3}{|c|}{ Actividades utilizadas para control de vectores } \\
\hline Método de & Fumigación & $46,3 \%$ \\
\hline control del & Desahumerio & $14,0 \%$ \\
\hline vector & Ninguna & $39,7 \%$ \\
\hline \multicolumn{3}{|c|}{ Tenencia de animales domésticos } \\
\hline Animales & Perros* & $41,0 \%$ \\
\hline domésticos & Gatos* & $31,0 \%$ \\
\hline & Aves de corral $* *$ & $28,0 \%$ \\
\hline
\end{tabular}

\subsection{Búsqueda activa activa comunitaria $\mathrm{e}$ institucional de casos}

Las 62 muestras de suero de niños con síntomas compatibles de la enfermedad, procesadas con pruebas Kalazar Detect ${ }^{\mathrm{TM}}$ Human Rapid Test [8] e IFI para la detección de anticuerpos IgG contra Leishmania infantum, fueron negativas para LV activa en $100 \%$ (62/62 todas dieron resultado negativo).

Se obtuvieron títulos bajos (1:8 y 1:16) e IDRM Reactiva en dos niñas familiares entre sí y convivientes en una de las viviendas ubicada en la parte alta del cerro, que se interpretaron como contacto previo con el parásito sin desarrollar enfermedad. Adicionalmente, se aplicaron IDRM a tres adultos y dos menores de esa misma vivienda, todas con resultados Reactivos. En esta casa se detectó Lu evansi dentro del domicilio.

El promedio de edad de los niños fue de 3,9 años, con un rango entre cinco meses y 13 años. El 82,6\% fueron menores de cinco años. El 52,2\% fueron niñas y el $47,8 \%$, niños. Los sintomas se describen en la tabla 2.

Tabla 2. Sintomatología casos sospechosos de búsqueda activa comunitaria.

\begin{tabular}{lc}
\hline Síntomas & Proporción $\%$ \\
\hline Fiebre prolongada & $36,5 \%$ \\
Malestar general & $23,8 \%$ \\
Irritabilidad & $14,3 \%$ \\
Pérdida de peso & $22,0 \%$ \\
Palidez & $17,4 \%$ \\
Falta de apetito & $41,2 \%$ \\
Hemorragias & $11,0 \%$ \\
Aumento del perímetro abdominal & $11,0 \%$ \\
Infecciones recurrentes & $51,7 \%$ \\
\hline
\end{tabular}

En la BAI se obtuvieron 22 muestras de pacientes que tenían historia clínica que cumplía con los criterios definidos; los resultados de IFI para LV procesados en el Laboratorio de Parasitología del INS fueron Negativos en un $100 \%$ de los niños. No se procesaron cultivos en medio NNN modificado debido a que todas las serologías no fueron reactivas.

\subsection{Estudio de reservorios caninos}

De las 13 muestras de ejemplares caninos procesadas por prueba Kalazar Detect ${ }^{\mathrm{TM}}$ Canine Rapid Test e IFI, una resultó positiva por ambos métodos (IFI 1:32), confirmándose como reservorio; solo este canino (1/13) presentó enflaquecimiento y uñas alargadas, síntomas compatibles con la enfermedad; las demás pruebas fueron negativas. La seroprevalencia fue de $7.69 \%$, y la concordancia de las pruebas, del $100 \%$. Tres caninos dieron títulos de 1:16 por IFI (asintomáticos), lo cual sugiere contacto con el parásito $[15,16]$. El canino confirmado fue eliminado de forma humanitaria por el grupo de zoonosis del distrito de Cartagena y un funcionario de la Sociedad Protectora de Animales, conforme al Protocolo de Vigilancia en Salud Pública vigente.

\subsection{Búsqueda de otros reservorios}

Se capturó en una trampa Tomahawk un macho Didelphis marsupialis (fara o zarigüeya), en el punto N10 25,233; W75 31,644; 65m. En medio NNN modificado se sembraron las muestras obtenidas a 
partir de tejidos, las cuales fueron negativas después de cinco semanas de incubación a $24-26^{\circ} \mathrm{C}$. En los fragmentos de bazo, hígado y ganglios linfáticos procesados, se demostró ADN de Leishmania sp.; el producto amplificado correspondió, según el patrón de peso molecular utilizado, a una banda de $120 \mathrm{pb}$, mediante la técnica de PCR con electroforesis en gel de agarosa (figura 3 ).

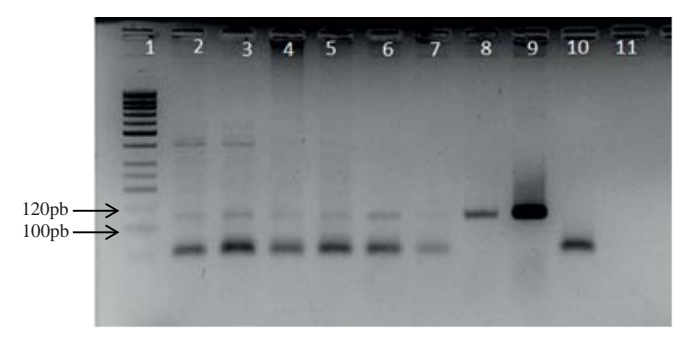

Figura 3.

La confirmación se realizó en el laboratorio de Pesquisa em Leishmaniose de la Fundação Oswaldo y dio resultado negativo para dos muestras de tejido (hígado y bazo) con el marcador utilizado HSP70, y una muestra de tejido (ganglio) positiva para Leishmania infantum.

Visualización de la electroforesis realizada en matriz de gel de agarosa al 1,5\% teñida con bromuro de etidio (0,5 microgramos/ml) (figura 3). De izquierda a derecha: Línea 1: se observa el marcador de peso molecular de 50 pares de bases, fermentans ${ }^{\circledR}$; Líneas 2 y 3: muestras de hígado. Líneas 4 y 5 : muestras de bazo. Líneas 6 y 7: muestras de ganglio. Líneas 8 y 9: muestras control positivo (Leishmania infantum y Leishmania. panamensis), Líneas 10 y 11: muestras controles negativos (agua destilada y Trypanosoma cruzi), la banda de amplificación corresponde según el patrón utilizado a 120 pb.

\subsection{Estudio entomológico}

Se recolectaron 113 flebótomos pertenecientes a cuatro especies, entre estas Lutzomyia evansi, vector del agente causal de la enfermedad [17]. La especie más abundante fue Lutzomyia trinidadensis, 78,76\% (89/113); seguida de Lutzomyia evansi, 11,5\% (13/113); Lutzomyia cayennensis, 6,2\% (7/113), у Lutzomyia venezuelensis, 3,54\% (4/113). L. evansi fue recolectada en el dormitorio en una de las viviendas y en el peridomicilio de otras tres viviendas, L. trinidadensis y L. cayennensis fueron recolectadas tanto en el intra como en el peridomicilio y Lu venezuelensis, en el peridomicilio. En la zona se distribuyeron toldillos Netprotect ${ }^{\circledR}$, que son insecticidas de larga duración en polietileno de alta densidad que contiene Deltametrina incorporada a la fibra distribuida de manera homogénea, y tienen un Mesh de 136 y 200 huecos por pulgada cuadrada. Este producto es aprobado por la Organización Mundial de la Salud Pesticide Evaluation Scheme (WHOPES), actúa como una barrera física y, además, tiene propiedades que inhiben la picadura, repelen el paso de los flebótomos, protegiendo así a las personas que duermen bajo el toldillo. En el barrio Lo Amador se distribuyeron en total 170 toldillos; se priorizó la vivienda del caso índice y las viviendas aledañas en donde habitaran niños menores de cinco años.

\section{Discusión}

El área de estudio corresponde a una zona de pobreza, lugar de residencia única del caso confirmado, en donde se demostró la presencia del vector y de reservorios silvestres y domésticos infectados, caracterizando así el foco urbano de LV en Cartagena.

La paciente presentó el cuadro clínico característico de LV, el cual fue confirmado por pruebas diagnósticas de laboratorio (Kalazar Detect ${ }^{\mathrm{TM}} \mathrm{Hu}-$ man Rapid Test (positiva) e IFI (1:32); los padres de la menor no refirieron desplazamientos a áreas de riesgo, un hecho que establece el origen de la enfermedad en el foco urbano de estudio. La corta evolución de la enfermedad en la niña podría explicar los títulos bajos de anticuerpos anti-leishmania y la moderada visceromegalia. El frotis de médula ósea fue negativo para leishmaniasis; sin embargo, es importante tener en cuenta que la sensibilidad de este método oscila entre 52 y $70 \%$ [18]. La anemia y la leucopenia reportadas en el hemograma son datos de laboratorio que dan soporte a la configuración del caso [1]. La buena respuesta al tratamiento es otra evidencia de la etiología de la enfermedad, así como la reactividad a la IDRM a los tres meses postratamiento.

La demostración de ADN del parásito en el hígado y el bazo del único Didelphis marsupialis capturado, conocido y descrito como reservorio de leishmaniasis visceral en otras regiones de Colombia [4, 5], confirma la presencia de reservorios clásicos para la transmisión de la LV, así como el resultado obtenido 
en la seroprevalencia de LV en el principal reservorio doméstico (caninos) del 7,69\%.

El hallazgo de Lutzomyia evansi dentro de las casas y en el peridomicilio del barrio es otra evidencia que confirma que el sitio de infección de la menor fue su vivienda, debido a que $L$. evansi se ha incriminado como vector de LV en la costa caribe colombiana [17], y en Venezuela también se considera vector alterno durante la estación húmeda, cuando disminuyen las poblaciones de L. longipalpis [20]. También se ha demostrado en México, Guatemala, El Salvador, Honduras, Nicaragua y Costa Rica [14, 20-21]. Se encuentra en los troncos de arbustos, y la transmisión ocurre en el intra- y el peridomicilio, tanto urbano como rural, desde los 0 a los $300 \mathrm{~m}$ [23].

Las viviendas limitan con zonas boscosas, secas y cálidas; las características ecológicas y las condiciones de pobreza, sumadas a los cambios en los patrones epidemiológicos de transmisión, fueron algunos de los factores que contribuyeron a la urbanización del ciclo de transmisión de esta parasitosis.

La BAC, realizada solo en los niños con sintomatología compatible para la enfermedad, no confirmó la existencia de otros casos de LV, pero permitió identificar títulos bajos de anticuerpos en dos niñas, lo cual sugiere contacto con el parásito vs. infección asintomática [19].

Las ocho pruebas de Montenegro aplicadas a los miembros de la familia donde se encontró $L$. evansi domiciliada fueron positivas; sin embargo, no se dispuso del reactivo para realizar el estudio poblacional que pudiera cuantificar la magnitud de la exposición a la enfermedad en el área, pero se propusieron las acciones de vigilancia y control regulares, por ser un foco activo y nuevo de la enfermedad.

Es importante mencionar los ejemplos de escenario de LV en expansión ocurridos en Brasil [23], situación agudizada por la existencia de confección con VIH [24], Paraguay (Asunción y Depto Central) y Argentina, una vez que se detectó el vector periurbano [25]. El Programa de Argentina comenzó con una alerta amarilla, cuando vigilancia entomológica detectó presencia del Lu longipalpis en territorio nacional en el año 2004, lo cual dio lugar a una alerta naranja. La consiguiente vigilancia de casos registró el primer caso humano autóctono en el año 2006; a partir de ese momento el vector se dispersó a cuatro provincias (primer nivel subnacional) del noreste y a Uruguay, con casos en tres provincias (una del área central, debido posiblemente a L. migonei). En el año 2013, los casos de LV humana autóctonos se notificaron en cuatro provincias, y se registró $L$. longipalpis en el noroeste, próximo a la frontera con Bolivia, y LV canina en todo el país por migración. Hasta el año 2014 se registraron 114 casos humanos, con una letalidad del 10,5\% (0-15 años: 8,3\%, > 60 años: $33,3 \%$ ) [25]. Por lo tanto, se hace necesario implementar una vigilancia regular y sostenida del evento que garantice su adecuado y oportuno control para evitar su expansión en el territorio estudiado y sus áreas limítrofes.

\section{Conclusiones}

Teniendo en cuenta los cambios epidemiológicos recientes, se debe sospechar LV en pacientes que presenten signos clínicos característicos de la enfermedad, incluso en áreas no endémicas, con el fin de hacer un diagnóstico temprano y reducir el riesgo de complicaciones y de muerte.

Debido al constante asentamiento de población en áreas periféricas, con condiciones sanitarias y de vida deficientes que aumentan el riesgo de infección por el contacto con animales domésticos y silvestres infectados, se hace necesario implementar de forma regular la vigilancia epidemiológica, entomológica, por laboratorio y de reservorios en el distrito de Cartagena, ya que tiene las condiciones ecoepidemiológicas propicias para la urbanización de la enfermedad.

Las pruebas parasitológicas (examen directo y cultivo en medio NNN modificado) son muy poco sensibles para el diagnóstico en caninos; así, las pruebas serológicas se constituyen en una herramienta esencial para detectar la condición de reservorios en estos, útiles para cuantificar la seroprevalencia y para la implementación óptima y oportuna de las acciones de control.

Para determinar el impacto real de la infección en las zonas endémicas es fundamental el empleo de pruebas diagnósticas eficientes, eficaces, accesibles y con resultados oportunos. Conforme a los lineamientos nacionales actuales, una prueba serológica de Kalazar Detect ${ }^{\mathrm{TM}}$ Human Rapid Test en niños 
con sintomatología compatible para L. visceral está considerada método de diagnóstico confirmatorio; de este modo se sensibiliza la detección, eliminando las barreras de acceso al diagnóstico oportuno, y se crea un primer paso para superar los inconvenientes de subregistro y subvaloración de la incidencia y la prevalencia de la enfermedad.

\section{Agradecimientos}

A los funcionarios del Grupo de Enfermedades Transmitidas por Vectores y Zoonosis del Departamento Administrativo Distrital de Salud de Cartagena D. T. y C. (DADIS) y de la Secretaría Departamental de Salud de Bolívar, por su apoyo y participación en el trabajo de campo realizado. A la Dra. Yanira Andrea Romero Barbosa, por su participación en el procesamiento de pruebas diagnósticas en humanos y caninos. Este trabajo fue financiado por el Instituto Nacional de Salud (INS), Bogotá, Colombia, y el Departamento Administrativo Distrital de Salud de Cartagena D. T. y C. (DADIS).

Los autores declaramos no tener conflicto de interés.

\section{Referencias}

[1] Protocolo de Vigilancia en Salud Pública Leishmaniasis. Minsalud-Instituto Nacional de Salud, Bogotá, 2014.

[2] C. González, O. Cabrera, L.E. Munstermann, and C. Ferro, "Distribución de los vectores de Leishmania infantum (Kinetoplastida: Tripasonomatidae) en Colombia”, Biomédica, vol. 26 (Supl 1), pp. 64- 72, octubre, 2006.

[3] A. Corredor, J. F. Gallego, R. B. Tesh, A. Morales, C. Ferro, D. Young et al., "Epidemiology of visceral leishmaniasis in Colombia", Am J Trop Med Hyg, vol. 40, no. 5, pp. 480-6, mayo, 1989.

[4] A. Corredor, J. F. Gallego, R. B. Tesh, D. Peláez, A. Díaz, M. Montilla, and M.T. Palau, "Didelphis marsupialis, an apparent wild reservoir of Leishmania donovani chagasi in Colombia, South America”, Trans Roy Soc Trop Med Hyg, vol. 83, no. 2, pp. 195, marzo-abril, 1989.

[5] B. Travi, C. Jaramillo, J. Montoya, Y. Segura, A. Zea, A. Goncalves, and I.D. Vélez, "Didelphis marsupialis, an important reservoir of Try- panosoma (Schizotrypanum) cruzi and Leishmania (Leishmania) chagasi in Colombia", Am J Trop Med Hyg, vol. 50, no. 5, pp. 557-65, mayo, 1994.

[6] B. L. Travi, Y. Osorio, M. T. Becerral, and G.H. Adler, "Dynamics of Leishmania chagasi infection in small mammals of the undisturbed and degraded tropical dry forests of northern Colombia", Trans. Roy. Soc. Trop. Med. Hyg., vol. 92, no. 3, pp. 275-8, May-June, 1998.

[7] C. Oddone, "Leishmaniosis visceral: a 101 años del primer caso diagnosticado en las Américas" Mem. Inst. Investig, Cienc. Salud, vol. 10, no. 1, pp. 102-104, junio 2012.

[8] E. Gadisa, E. Custodio, C. Canavate, L. Sordo, Z. Abebe et al., "Usefulness of the rK39immunochromatographic test, direct agglutination test, and leishmanin skin test for detecting asymptomatic Leishmania infection in children in a new visceral leishmaniasis focus in Amhara State, Ethiopia”, Am. J. Trop. Med. Hy.g vol 86, no. 5, pp. 792-798, May, 2012.

[9] R. J. Quinnell, C. Carson, R. Reithinger, L. M. Garcez, and O. Courtenay, "Evaluation of rk39 rapid diagnostic test for canine visceral leishmaniasis. Longitudinal study and metaanalysis", PLoS. Negl. Trop. Dis., Vol. 7, no. 1, pp. e1992, January, 2013.

[10] A. L. Roque, S. C. Xavier, M. G. da Rocha, A. C. Duarte, P. S. D'Andrea, and A. M. Jansen, "Trypanosoma cruzi transmission cycle among wild and domestic mammals in three areas of orally transmitted Chagas disease outbreaks", Am. J. Trop. Med. Hyg., vol. 79, no. 5, pp. 742749, November, 2008.

[11] L. Nicolas, S. Sidjanski, J. H. Colle, and G. Milon, "Leishmania major reaches distant cutaneous sites where it persists transiently while persisting durably in the primary dermal site and its draining lymph node: a study in laboratory mice", Infect. Immun., vol. 68, no. 12, pp. 6561-6, December, 2000.

[12] G. C. da Graça, A. C. VolpiniI, G. A. Sierra, M. P. de Oliveira, M. H. Renato, M. Côrtes, and E. Cupolillo, "Development and validation of PCR-based assays for diagnosis of American cutaneous leishmaniasis and identification of 
the parasite species", Mem. Inst. Oswaldo Cruz, vol. 107, no. 5, pp. 664-674, August, 2012.

[13] C. B. Marcondes, "An improved technique for the disection of female genitalia of phlebotomine sandflies (Diptera Psychodidae) with an improvement in the handing of insects", Mem. Inst. O. Cruz, vol. 93, no. 1, pp. 109, JanuaryFebruary, 1998.

[14] D. Young, and M. Duncan, "Guide to the identification and geographic distribution of Lutzomyia sand flies in Mexico, the West Indies, Central and South America (Diptera; Psychodidae)", Mem. Amer. Ent. Inst., vol. 54, pp. 1-881. 1994.

[15] M. Romero, M. C. López, M. C. Echeverry, and F. Rivas, "Leishmaniasis Visceral Canina: Pruebas diagnósticas no identifican Estados Reales de la Infección”, Rev. Salud pública, vol. 10, no. 2, pp. 290-98, marzo-mayo, 2008.

[16] J. Fernández, F. Bello, M. C. López, L. I. Moncada, J. J. Vargas, M. S. Ayala, R. S. Nicholls, and C. A. Lozano, "Seroprevalencia de leishmaniasis visceral canina en el sector 8 de Neiva y 4 municipios de Huila, Colombia", Biomedica, vol. 26, no. 1, pp. 121-30, octubre, 2006.

[17] B. L. Travi, I. D. Vélez, L. Brutus, I. Segura, C. Jaramillo, and J. Montoya, "Lutzomyia evansi, an alternate vector of Leishmania chagasi in a Colombian focus of visceral leishmaniasis", Trans. R Soc. Trop. Med. Hygiene, vol. 84, no. 5, pp. 676-7, September, 1990.

[18] M. Gállego, C. Riera, "Las leishmaniosis humanas: Leishmaniosis autóctona por Leishmania infantum", Unitat de Parasitologia, Departament de Microbiología y Parasitología Sanitàries, Facultat de Farmàcia, Universitat de Barcelona, Control Calidad SEIMC, Barcelona, 2000.

[19] N. Añez, A. Rojas, E. Vargas-Díaz, V. Medina, G. Crisante, J. Y. Yépez, "Estudio epidemiológico sobre leishmaniasis visceral en la región semiárida del occidente de Venezuela con especial referencia a la detección de infecciones inaparentes", Bol. Mal. Salud Amb., vol. 52. no. 2, pp. 245-256. Diciembre, 2012.

[20] J. Montoya-Lerma, C. Ferro. "Flebótomos (Diptera: Psychodidae) de Colombia" Insectos de Colombia", vol. II. Colección Jorge Álvarez Lleras, no. 13. Santa Fe de Bogotá: Academia Colombiana de Ciencias Exactas, Físicas y Naturales-Centro Editorial Javeriano, pp. 21145, 1999.

[21] D. G. Young, "A review of the bloodsucking psychodid flies of Colombia (Diptera: Phlebotominae and Sycoracinae)", Technical Bulletin 806. Gainesville: Institute of Food and Agricultural Sciences, University of Florida, pp. 266, 1979.

[22] L. A. Cortés, J. J. Fernández, "Especies de Lutzomyia en un foco urbano de leishmaniasis visceral y cutánea en El Carmen de Bolívar, Bolívar, Colombia", Biomédica, vo. 28, no. 3, pp. 433-40, Septiembre, 2008.

[23] P. Albuquerque, G. J. da Silva, C.C. Freire, S. Oliveira, D.M. Almeida, H.F. da Silva et al., "Urbanization of visceral leishmaniasis (kalaazar) in Fortaleza, Ceará, Brazil", Rev. Panam. Salud Publica/Pan. Am. J. Public. Health, vol. 26, 330-3, 2009.

[24] J. Alvar, P. Aparicio, A. Aseffa, M. Den Boer, C. Cañavate, J. P. Dedet, L. Gradoni, R. Ter Horst, R. López-Vélez, J. Moreno, "The Relationship between Leishmaniasis and AIDS: the Second 10 Years", Clin. Microbiol. Rev., vol. 21, no. 2, pp. 334-359, April, 2008.

[25] Organización Mundial de La Salud (OMS), Organización Panamericana de la Salud (OPS), "Informe final segunda reunión de gerentes de programas de leishmaniasis de las Américas", Oficina regional para las Américas, Ciudad de Panamá, 8 al 10 de octubre de 2013. 